\title{
ASPECTOS HISTOQUímiCOS DO PLEXO MIENTÉRICO NA DOENÇA DE CHAGAS EXPERIMENTAL
}

\author{
Plinio Garcez de Sena * \\ Moysés Teles Filho **
}

As alterações do sistema nervoso na moléstia de Chagas experimental têm sido objeto de várias publicações, sendo particularizada a descrição de quadros histológicos (Köberle 6, 7,8,9 e Brandão ${ }^{10}$ ). Brandão avaliou quantitativamente os neurônios simpáticos e parassimpáticos no mal de Chagas experimental em sua fase crônica, observando haver "diminuição estatìsticamente não significativa dos neurônios simpáticos dos ratos chagásicos, em confronto com uma redução numérica estatìsticamente significante dos parassimpáticos". Köberle pensa que tais alteraçōes, verificadas na fase crônica da doença experimental, se instalam durante o periodo agudo, quando se decide o destino do paciente chagásico.

Sabendo-se que o parasitismo antecede às alterações neuronais, nos propusemos analisar, em fase aguda, os plexos mientéricos do ponto de vista enzimático.

\section{MATERIAL E METODOS}

De um lote de 20 ratos albinos, pesando entre 25 e $30 \mathrm{~g}$, inoculamos 10 com a cêpa $Y$ do Trypanosoma cruzi, na dose de $0,10 \mathrm{ml}$ por via intraperitoneal, sendo os animais examinados cada 48 horas. O exame parasitémico foi feito a fresco, entre lâmina e laminula, com sangue retirado da cauda do animal. A parasitemia foi verificada a partir do $3^{\circ}$ dia de inoculaçāo, sendo encontrados 35 a 40 tripanosomas, em média, por campo microscópico.

Os ratos infectados morreram na fase aguda da doença entre o $8^{\circ}$ e $13^{\circ}$ dias após a inoculação. Secçōes representativas do aparelho gastrintestinal (intestino delgado e cólon) foram fixadas em acetona a $4^{\circ} \mathrm{C}$ e formol tamponado à mesma temperatura: os espécimes fixados em formol foram impregnados pela prata, segundo variante do método de Gross-Bielschowsky, em cortes por congelação; segmentos intestinais fixados em acetona gelada foram utilizados para demonstração da atividade esterásica.

Também foram feitas inclusōes em parafina de material proveniente tanto dos animais parasitados como dos animais contrôle, sendo as inclusões cortadas com espessura de 8 micra, em séries de 25 cortes sucessivos, totalizando uma espessura de 200 micra. Estes cortes foram corados pela hematoxilina-eosina e usados para estudo comparativo das possiveis alterações morfológicas entre os dois lotes.

Professor Adjunto de Clínica Neurológica na Universidade da Bahia; ** Do Serviço de Neuropatologia da Universidade da Bahia. 


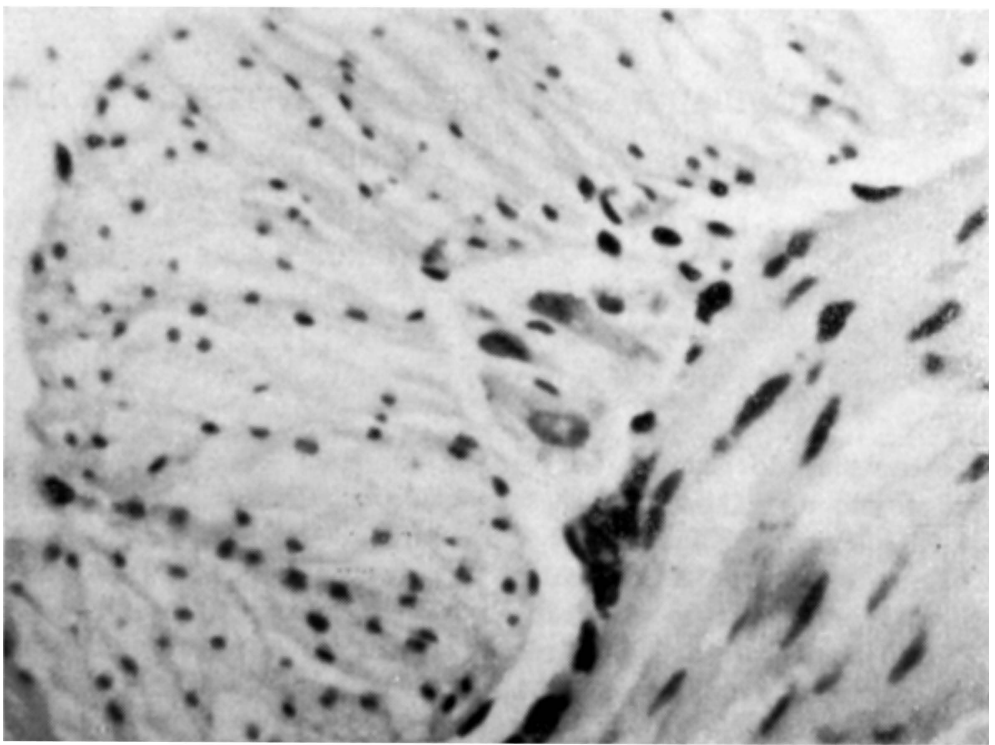

Fig. 1 - Seccão ao nivel do plexo mientérico (parede intestinal), mostrando 4 neurónios intactos em animal infectado $e$ durante a fase

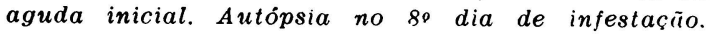

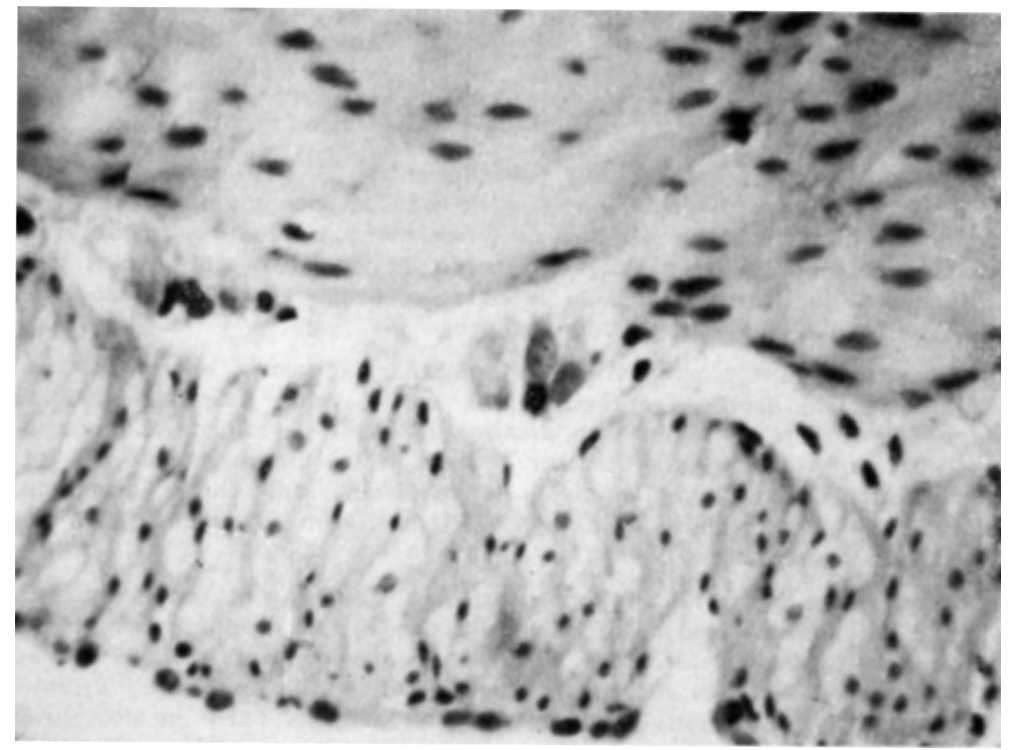

Fig. 2 - Secçĩo mostrando gânglios parassimpáticos contendo neurônios igualmente conservados de animal do grupo contrôle. Autópsia no $8^{\circ}$ dia de experimentació. 


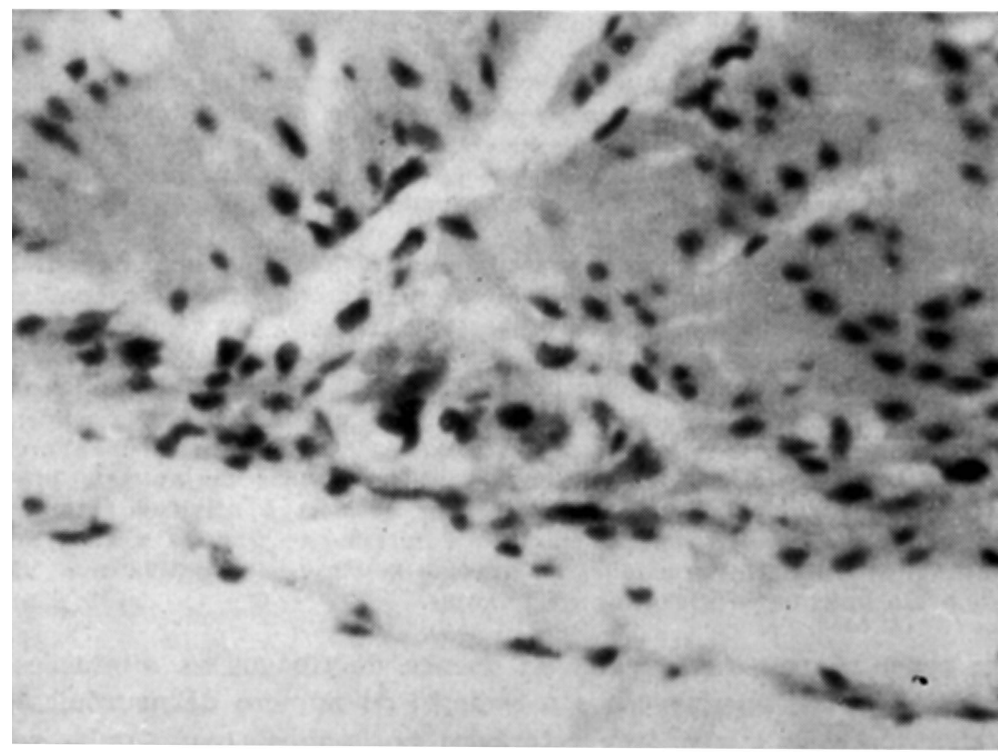

Fig. 3. - Gânglio parassimpático contendo neurônios bem conservados em animal com parasitemia, sacrificado no $19^{\circ}$ dia após infestacão.

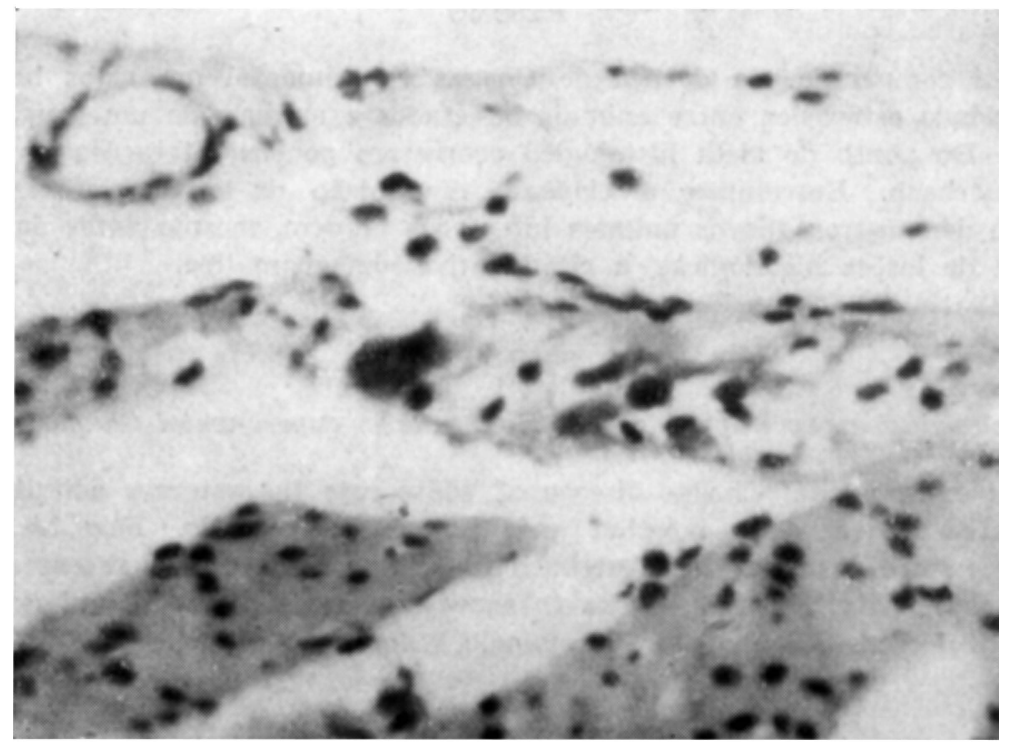

Fig. 4 - Microfotografia comparativa de animal do grupo contrôle, sacrificado no 190 dia. Aspecto histológico semelhante ao de animal infestado com a mesma duração de tempo. 


\section{RESULTADOS}

Na sua quase totalidade, quando examinados comparativamente espécimes d $s$ animais parasitados e contrôle, as células nervosas do plexo de Auerbach mostráram algumas alteraçōes provàvelmente devidas à fixação, exibindo certo grau che hipercromatismo em determinadas áreas e descoloramento em outras, o que nlio dificultou a comparação quantitativa, muito embora não fôsse êsse o nosso interêsse no presente trabalho.

Nas seccões impregnadas pela prata, tanto o lote dos animais parasitados quanto os animais do grupo contrôle mostraram neurônios bem conservados, ccim seus prolongamentos axiais e dendriticos bastante visiveis. As células gliais envolvendo êsses neurônios se apresentavam, quando comparadas às dos animais năo parasitados, dentro dos limites normais.

Os espécimes fixados em acetona gelada foram utilizados para a evidenciaçăo da atividade esterásica. As secções foram deixadas no meio da incubação durante 15', 30' e 60', passando-se a comparar as secçoes obtidas de animais infectadcs com as do lote testemunho; para êstes últimos animais a atividade esterásica se mostrou fracamente positiva aos 15 minutos e fortemente positiva aos 60 minutos; em relação aos animais parasitados, a reação mostrou-se negativa aos 15 e 30 minutos, e fracamente positiva aos 60 minutos.

Em conclusão, na fase aguda da doença de Chagas as alterações morfológicas dos plexos mientéricos e a redução do número de neurônios foram pouco significativas; a atividade esterásica nos animais parasitados se mostrou diminuída, sendo presente nos animais do grupo contrôle. Assim, parece haver, no estado agudo da doença, diminuição da atividade esterásica antes mesmo da aparição de alteraçōes morfológicas.

\section{RESUMO}

Foi comparada, na doença de Chagas experimental em ratos brancos, a atividade esterásica entre animais infectados e animais de um grupo contrôle. Do ponto de vista histológico ocorreram poucas alterações no plexo de Auerbach. Entretanto, a evidente diminuição da atividade esterásica parece demonstrar que os animais infectados perdem, mesmo antes da ocorrência de lesões histológicas, a citada atividade enzimática.

\section{SUMMARY}

Histochemical aspects of the myenteric plexus in experimental Chagas disease

In experimental Chagas disease of white rats the esterase activity was compared between the infected and the control animals. Few histologic changes were found at the Auerbach plexus. The marked decrease of the esterase activity, however, seems to show that in the infected animals this activity decreases even before hystologic lesions are evident.

\section{REFERENCIAS}

1. KOBERLE, F. - Fisiopatologia da moléstia de Chagas. Anais da IV Reunião da Associação Latino-Americana de Ciências Fisiológicas, Ribeirão Prêto, jutho, 1962 . 
2. KOBERLE, F. - Chagas's disease: its pathogenesis and significance as an epidemic. Z. Tropenmed. Parasit. 10:236, 1959.

3. KOBERLE, F. - Patogenia da moléstia de Chagas. Estudo dos órgãos musculares ôcos. Rev. Goiana Med. 3:155, 1957.

4. KoBERLE, F. - Cardiopatia chagásica. O Hospital (Rio de Janeiro) 53:9, 1958.

5. KOBERLE, F. - Patofisiologia da moléstia de Chagas. II Congresso LatinoAmericano de Anatomia Patológica, São Paulo, 1958.

6. KOBERLE, F. - Aperistalsis chagásica do intestino grosso: estudo quantitativo dos neurônios do plexo de Auerbach. Congresso Internacional sôbre a Doença de Chagas, Rio de Janeiro, 1959.

7. KOBERLE, F. - Bronquiectasia chagásica: estudo quantitativo dos neurônios da árvore brônquica. Congresso Internacional sôbre a Doença de Chagas, Rio de Janeiro, 1959.

8. KOBERLE, F. - Cardiopathia parasympathicopriva. Münchn. Med. Wschr. $101: 1308,1959$.

9. KOBERLE, F. \& ALCÂNTARA, F. G. - Mecanismo da destruição neuronal do sistema nervoso periférico na moléstia de Chagas. O Hospital (Rio de Janeiro) $57: 1057,1960$.

10. BRANDAO, H. J. S. - Moléstia de Chagas experimental: estudo quantitativo dos neurônios simpáticos e parassimpáticos. O Hospital (Rio de Janeiro) 61: 137, 1962.

Clinica Neurológica - Faculdade de Medicina da Universidade da Bahia Salvador, BA - Brasil. 